\title{
Hydro Magnetic Free Convection Mass Transfer Flow of A Polar Fluid on A Vertical Porous Plate with Couple Stress in Slip Flow Regime
}

\author{
H. Singh ${ }^{1}$ and N.C. Jain ${ }^{2}$ \\ ${ }^{1}$ Department of Mathematics, Jaipur National University Jaipur-302017, INDIA \\ ${ }^{2}$ Department of Mathematics, University of Rajasthan Jaipur-302055, INDIA
}

\begin{abstract}
This paper examines the problem of MHD steady mass transfer flow of a polar fluid through a porous medium bounded by an infinite vertical porous plate in slip flow regime. In the mass transfer equation effect of thermal diffusivity which plays an important role in the flow is also considered. The exact solutions for velocity field, angular velocity field, temperature distributions and concentration field are obtained. The expression for the skin-friction, the rate of heat transfer are also derived. Effects of rotational parameter $(\alpha)$, couple stress parameter $(\beta)$ and other parameter entered into the problem are examined with the help of graphs. It is found that the velocity of the fluid is increased when the rotational parameter is increased but decreased in case of couple stress parameter.
\end{abstract}

Key words: Magnetic field, Mass transfer, Porous medium, Rotational velocity, Thermal diffusion.

\section{Introduction}

The study of the flow through a porous medium under the influence of a magnetic field has attracted the interest of many investigators in view of its applications in many engineering problems such as mangetohydrodynamic generator, plasma studies, nuclear reactors, oil exploration, geothermal energy extractions and the boundary layer control in the field of aerodynamics. Also, free convection flows are of great interest in a number of industrial applications such as fiber and granular insulation, geothermal etc. magnetohydrodynamics has attracted the attention of a large number of scholars due to its diverse applications.

In astrophysics and geophysics, it is applied to study the stellar and solar structures, interstellar matter, radio propagation through the ionosphere etc. in engineering, it finds its applications in MHD pumps, MHD bearings etc. Brinkmann [1], Chawla and Singh [2], Yamamoto and Yoshida [3] have discussed fluid flow through porous medium considering generalized Darcy's law which contains the terms of viscous stress and convection acceleration. Convection in porous media has applications in geothermal energy recovery, oil extraction, thermal energy storage and flow through filtering devices is given in the book of Nield and Bejan [4]. In all above works, generalized Darcy's law is derived without taking into account the angular velocity of the fluid particles.

Aero et al. [5] derived and solved the flow equations fo the fluid in which angular velocity of the fluid particles was taken into account. These fluids are known as polar fluids in the literature and are more general than ordinary fluids Lukaszewicz [6]. Rapits et al. [7], Raptis and Takhar [8] have discussed polar flow through porous medium. Recently Saxena and Dubey [9], Jain et al. [10], Jain and Gupta [11, 12] considered magnetic effects on polar flow. Polar fluids belong to a class of fluids with microstructure and have asymmetrical stress tensor. Physically, they represent fluids consisting of randomly oriented particles suspended in a viscous medium. Some authors viz. Ahmadi [13], Kim [14] used the word micropolar in place of polar because of the microstrucure property of the fluid particles. From technological point of view, MHD free convection flows have significant applications in the field of stellar and planetary magnetosphere, aeronautics, chemical engineering and electronics on account of their varied importance, these flows have been studied by several authors notable amongst them are Shercliff [15]. Ferraro and Plumpton [16] and Cramer [17].

Radiative convective flows are encountered in countless industrial and environment processes, such as heating and cooling chambers, fossil fuel combustion energy processes evaporation from large open Watter reservoirs, astrophysical flows, solar power technology and space vehicle re-entry. England and Emery [18] have studied the thermal radiation effects of an optically thin gray gas bounded by a stationary plate.

Chandrakala and Antomy Raj [19], Soundalgekar and Takhar [20] have considered the radiative free convective flow past a semi-infinite vertical plate. As slip boundary conditions are very useful in geothermal region in which situations may arise when the flow becomes unsteady and slip at the boundary takes place. Recently Jothimani and Anjali Devi [21] and Khandelwal and Jain [22] have considered the slip boundary conditions in their heat flow problems. 
In the present study, we can consider electrically conducting steady polar flow through porous medium in slip flow regime under the influence of radiative heat. As whole of the body is not rotating but only randomly oriented fluid particles are rotating. Coriolis force is not considered (French and Norton [23]) in this problem.

Obtaining exact solutions, effects of different parameters entering into the problem namely $\mathrm{K}$ (permeability parameter), $\mathrm{M}$ (magnetic parameter), $\alpha$ (kinematic rotational viscosity parameter), $\mathrm{h}_{1}$ (velocity slip parameter), $\beta$ (couple stress parameter), Gr (thermal Grashof number), Gc (mass Grashof number), So (soret number), Sc (Schmidt number), S (radiation parameter) and Pr (Prandtl number) are discussed on the velocity field, angular velocity and temperature, concentration, skin friction and quantity of heat transfer and are shown graphically.

\section{Mathematical formulation and solutions of the problem}

We consider the two dimensional, steady, free convective flow with mass transfer and thermal diffusion of an electrically conducting polar fluid through a porous medium in slip flow regime past an infinite vertical porous plate in presence of a heat source/sink. A magnetic field of uniforms strength is applied transversely to the direction of the flow. The magnetic Reynolds number of the flow is taken to be small enough so that the induced magnetic field can be neglected. We taken the $\mathrm{x}$-axis along the plate and y-axis normal to it and the flow in the medium is entirely due to buoyancy force caused by temperature difference between the wall and the fluid. The suction velocity $v_{\mathrm{o}}$ and permeability $\mathrm{K}$ of the porous medium are constant.

Under these conditions using the Boussineque's approximation equations, governing the flow are given as :

Continuity equation

$$
\frac{\partial v}{\partial y}=0
$$

Linear momentum equation

$$
v \frac{\partial u}{\partial y}=g \beta\left(T-T_{\infty}\right)+g \beta^{1}\left(C-C_{\infty}\right) \frac{1}{\rho}\left(\mu+\mu_{r}\right) \frac{\partial^{2} u}{\partial y^{2}}+\frac{2}{\rho} \mu_{r} \frac{\partial \omega}{\partial y}-\frac{v u}{K}-\frac{\sigma \mu_{e} B^{2} u}{\rho}
$$

Angular momentum equation

$$
v \frac{\partial \omega}{\partial y}=\frac{\gamma}{I} \frac{\partial^{2} \omega}{\partial y^{2}}
$$

Energy equation

$$
v \frac{\partial \mathrm{T}}{\partial \mathrm{y}}=\frac{\mathrm{k}}{\rho \mathrm{C}_{\mathrm{p}}} \frac{\partial^{2} \mathrm{~T}}{\partial \mathrm{y}^{2}}-\frac{1}{\rho \mathrm{C}_{\mathrm{p}}} \frac{\partial \mathrm{q}_{\mathrm{r}}}{\partial \mathrm{y}}
$$

Concentration equation

$$
v \frac{\partial \mathrm{c}}{\partial \mathrm{y}}=\mathrm{D} \frac{\partial^{2} \mathrm{~T}}{\partial \mathrm{y}^{2}}+\mathrm{D} \ell \frac{\partial^{2} \mathrm{~T}}{\partial \mathrm{y}^{2}}
$$

Here $\rho$ denotes the density, u the velocity along the $\mathrm{x}$-direction and $\nu$ the velocity along the $\mathrm{y}$-axis, $\mu$ the viscosity of the fluid $\mu_{\mathrm{r}}$ the rotational viscosity, B the strength of magnetic field, $\omega$ and T are mean angular velocity and temperature of fluid particles. $\sigma$ is fluid conductivity, $\mu_{\mathrm{e}}$ is magnetic permeability. D is the coefficient of chemical molecular diffusivity, $\mathrm{D} \ell$ is thermal diffusivity. I a scalar constant of dimension equal to that of moment of ineria of unit mass and

$$
\gamma=\mathrm{C}_{\mathrm{a}}+\mathrm{C}_{\mathrm{d}}
$$
meanings.

where $C_{a}$ and $C_{d}$ are coefficient of couple stress viscosities. Remaining symbols have their usual

The boundary conditions are :

$$
\begin{aligned}
& \mathrm{u}=\mathrm{L}_{1} \frac{\partial \mathrm{u}}{\partial \mathrm{y}}, \quad \frac{\partial \omega}{\partial \mathrm{y}}=-\frac{\partial^{2} \mathrm{u}}{\partial \mathrm{y}^{2}}, \quad \mathrm{~T}=\mathrm{T}_{\mathrm{w}}, \mathrm{C}=\mathrm{C}_{\mathrm{w}} \quad \text { at } \mathrm{y}=0 \\
& \mathrm{u} \rightarrow 0, \omega \rightarrow 0, \mathrm{~T} \rightarrow \mathrm{T}_{\infty}, \mathrm{C} \rightarrow \mathrm{C}_{\infty} \text { as } \mathrm{y} \rightarrow \infty \\
& \text { where } \mathrm{L}_{1}=\left(\frac{2-\mathrm{m}_{1}}{\mathrm{~m}_{1}}\right) \mathrm{L}, \mathrm{L} \text { being mean free path and } \mathrm{m}_{1} \text { the Maxwell's reflection coefficient. }
\end{aligned}
$$

Integration of equation (2.1) for constant suction gives : 
$v=v_{0}$

The radiative heat flux $\mathrm{q}_{\mathrm{r}}$ is considered as

$$
\frac{\partial \mathrm{q}_{\mathrm{r}}}{\partial \mathrm{y}}=4\left(\mathrm{~T}-\mathrm{T}_{\infty}\right) \mathrm{I}_{1}
$$

where $\mathrm{I}_{1}=\int_{0}^{\infty} \mathrm{K}_{\lambda \mathrm{n}} \frac{\partial \mathrm{e}_{\mathrm{b} \lambda}}{\partial \mathrm{T}} \mathrm{d} \lambda$,

Introducing the following non-dimensional quantities

$\mathrm{u}^{*}=\frac{\mathrm{u}}{\mathrm{v}_{0}}, \quad \mathrm{y}^{*}=\frac{\mathrm{yv_{0 }}}{\mathrm{v}}, \quad \omega^{*}=\frac{\omega \mathrm{v}}{\mathrm{v}_{0}}$,

$\mathrm{K}^{*}=\frac{\mathrm{K} v_{0}^{2}}{\mathrm{v}^{2}}, \quad \phi=\frac{\mathrm{C}-\mathrm{C}_{\infty}}{\mathrm{C}_{\mathrm{w}}-\mathrm{C}_{\infty}}, \theta=\frac{\mathrm{T}-\mathrm{T}_{\infty}}{\mathrm{T}_{\mathrm{w}}-\mathrm{T}_{\infty}}$

$\alpha=\frac{v_{\mathrm{r}}}{\mathrm{v}}$ (Rotational parameter), $\beta=\frac{\mathrm{I} \mathrm{v}}{\gamma}$ (Couple stress parameter)

$\mathrm{M}^{2}=\frac{\sigma \mu_{\mathrm{e}} \mathrm{B}^{2} \mathrm{v}}{\rho v_{0}^{2}}$ (Magnetic field parameter),

$\mathrm{Gr}=\frac{\operatorname{vg} \beta\left(\mathrm{T}_{\mathrm{w}}-\mathrm{T}_{\infty}\right)}{v_{0}^{3}}$ (Thermal Grashof number),

$\mathrm{Gc}=\frac{\nu \mathrm{g} \beta^{1}\left(\mathrm{C}_{\mathrm{w}}-\mathrm{C}_{\infty}\right)}{v_{0}^{3}}$ (Mass Grashof number), Pr $=\frac{\mu \mathrm{C}_{\mathrm{p}}}{\mathrm{k}}$ (Prandtl number),

$\mathrm{S}=\frac{4 \mathrm{vI} \mathrm{I}_{1}}{\rho \mathrm{C}_{\mathrm{p}} \mathrm{v}_{0}^{2}}$ (Radiation parameter), $\quad \mathrm{h}_{1}=\frac{\mathrm{L}_{1} \mathrm{v}_{0}}{\mathrm{v}}$ (Velocity slip parameter),

$\mathrm{Sc}=\frac{\mathrm{v}}{\mathrm{D}}$ (Schmidt number), $\mathrm{S}_{0}=\frac{\mathrm{D} \ell\left(\mathrm{T}_{\mathrm{w}}-\mathrm{T}_{\infty}\right)}{\mathrm{v}\left(\mathrm{C}_{\mathrm{w}}-\mathrm{C}_{\infty}\right)}$ (Soret number $)$

In view of equations (2.7), (2.8) the equations of motion in non-dimensional form after dropping the asterisks over them, reduced to :

$$
\begin{aligned}
& (1+\alpha) \frac{\partial^{2} \mathrm{u}}{\partial \mathrm{y}^{2}}+\frac{\partial \mathrm{u}}{\partial \mathrm{y}}+2 \alpha \frac{\partial \omega}{\partial \mathrm{y}}+\mathrm{Gr} \theta+\mathrm{Gc} \phi-\mathrm{N}^{2} \mathrm{u}=0 \\
& \frac{\partial^{2} \omega}{\partial \mathrm{y}^{2}}+\beta \frac{\partial \omega}{\partial \mathrm{y}}=0 \\
& \frac{\partial^{2} \theta}{\partial \mathrm{y}^{2}}+\operatorname{Pr} \frac{\partial \theta}{\partial \mathrm{y}}-\operatorname{Pr} \mathrm{S} \theta=0 \\
& \frac{\partial^{2} \phi}{\partial \mathrm{y}^{2}}+\operatorname{Sc} \frac{\partial \phi}{\partial \mathrm{y}}-\mathrm{S}_{0} \mathrm{Sc} \frac{\partial^{2} \theta}{\partial \mathrm{y}^{2}}=0
\end{aligned}
$$

With corresponding boundary conditions as

$$
\begin{aligned}
& \mathrm{u}=\mathrm{h}_{1} \frac{\partial \mathrm{u}}{\partial \mathrm{y}}, \quad \frac{\partial \omega}{\partial \mathrm{y}}=-\frac{\partial^{2} \mathrm{u}}{\partial \mathrm{y}^{2}}, \quad \theta=1, \phi=1 \text { at } \mathrm{y}=0 \\
& \mathrm{u} \rightarrow 0, \omega \rightarrow 0, \theta \rightarrow 0, \phi \rightarrow 0 \text { as } \mathrm{y} \rightarrow \infty \\
& \text { where } \mathrm{N}^{2}=\mathrm{M}^{2}+\frac{1}{\mathrm{~K}}
\end{aligned}
$$


Solving the equations (2.9) to (2.12), we get the following exact solution after using corresponding boundary conditions (2.13) :

$$
\begin{aligned}
& \mathrm{u}=\mathrm{C}_{5} \mathrm{e}^{-\mathrm{R}_{1} \mathrm{y}}-\mathrm{E}_{1} \mathrm{C}_{1} \mathrm{e}^{-\beta y}+\left(\mathrm{E}_{2} \mathrm{C}_{2}-\mathrm{E}_{4} \mathrm{C}_{4}\right) \mathrm{e}^{-\mathrm{R}_{3} \mathrm{y}}+\mathrm{E}_{3} \mathrm{C}_{3} \mathrm{e}^{- \text {Scy }} \\
& \omega=\mathrm{C}_{1} \mathrm{e}^{-\beta y} \\
& \theta=\mathrm{C}_{2} \mathrm{e}^{-\mathrm{R}_{3} \mathrm{y}} \\
& \phi=\mathrm{C}_{3} \mathrm{e}^{-\mathrm{Scy}}-\mathrm{C}_{4} \mathrm{e}^{-\mathrm{R}_{3} \mathrm{y}}
\end{aligned}
$$

\section{Skin friction and Nusselt number}

The skin-friction due to velocity is given by

$$
\tau_{\mathrm{w}}=\left(\mu+\mu_{\mathrm{r}}\right)\left(\frac{\partial \mathrm{u}}{\partial \mathrm{y}}\right)_{\mathrm{y}=0}
$$

In non-dimensional form after dropping the asterisk

$$
\tau=\frac{\tau_{\mathrm{w}}}{\rho v_{0}^{2}}=(1+\alpha)\left\{-\mathrm{R}_{1} \mathrm{C}_{5}+\beta \mathrm{E}_{1} \mathrm{C}_{1}+\left(\mathrm{E}_{4} \mathrm{C}_{4}-\mathrm{E}_{2} \mathrm{C}_{2}\right) \mathrm{R}_{3}-\mathrm{ScE}_{3} \mathrm{C}_{3}\right\}
$$

Another important parameter, the rate of heat transfer is given by

$$
\mathrm{Nu}=\frac{-\mathrm{L}_{1}}{\left(\mathrm{~T}_{\mathrm{w}}-\mathrm{T}_{\infty}\right)}\left(\frac{\partial \mathrm{T}}{\partial \mathrm{y}}\right)_{\mathrm{y}=0}
$$

In non-dimensional form after dropping the asterisk

Where$$
\mathrm{Nu}=\mathrm{h}_{1} \mathrm{C}_{2} \mathrm{R}_{3}
$$

$$
\begin{aligned}
& \mathrm{C}_{1}=\frac{\left(\mathrm{R}_{1}^{2} \mathrm{C}_{5}+\mathrm{K}_{1}\right)}{\beta\left(1+\beta \mathrm{E}_{1}\right)}, \quad \mathrm{C}_{2}=1, \quad \mathrm{C}_{3}=1+\mathrm{C}_{4} \\
& C_{4}=\frac{S_{0} S_{c} R_{3} R_{2}}{\left(R_{3}-S c\right)}, \quad C_{5}=\frac{E_{1}\left(1+\beta h_{1}\right) K_{1}-\beta\left(1+\beta E_{1}\right) K_{2}}{\beta\left(1+\beta E_{1}\right)\left(1+h_{1} R_{1}\right)-R_{1}^{2} E_{1}\left(1+\beta h_{1}\right)}
\end{aligned}
$$

$\mathrm{K}_{1}=\mathrm{R}_{2}^{3} \mathrm{E}_{2}+\mathrm{Sc}^{2} \mathrm{E}_{3} \mathrm{C}_{3}+\mathrm{R}_{2}^{3} \mathrm{E}_{4} \mathrm{C}_{4}$

$$
\mathrm{K}_{2}=\mathrm{R}_{3} \mathrm{E}_{2} \mathrm{~h}_{1}+\mathrm{E}_{3} \mathrm{~h}_{1} \mathrm{ScC}_{3}-\mathrm{R}_{3} \mathrm{E}_{4} \mathrm{~h}_{1} \mathrm{C}_{4}+\mathrm{E}_{2}+\mathrm{E}_{3} \mathrm{C}_{3}-\mathrm{E}_{4} \mathrm{C}_{4}
$$

$$
\mathrm{R}_{1}=\frac{1+\sqrt{1+4(1+\alpha) \mathrm{N}^{2}}}{2(1+\alpha)}, \quad \mathrm{R}_{2}=\frac{-1+\sqrt{1+4(1+\alpha) \mathrm{N}^{2}}}{2(1+\alpha)}
$$$$
\mathrm{R}_{3}=\frac{\operatorname{Pr}+\sqrt{\operatorname{Pr}^{2}+4 \operatorname{Pr} \mathrm{S}}}{2},
$$$$
E_{1}=\frac{2 \alpha \beta}{(1+\alpha)\left(R_{1}+\beta\right)\left(R_{2}-\beta\right)}
$$

$$
\mathrm{E}_{2}=\frac{\mathrm{Gr}}{(1+\alpha)\left(\mathrm{R}_{1}+\mathrm{R}_{3}\right)\left(\mathrm{R}_{2}-\mathrm{R}_{3}\right)} \text {, }
$$$$
\mathrm{E}_{3}=\frac{\mathrm{Gc}}{(1+\alpha)\left(\mathrm{R}_{1}+\mathrm{Sc}\right)\left(\mathrm{R}_{2}-\mathrm{Sc}\right)}
$$

$$
\mathrm{E}_{4}=\frac{\mathrm{Gc}}{(1+\alpha)\left(\mathrm{R}_{1}+\mathrm{R}_{3}\right)\left(\mathrm{R}_{2}-\mathrm{R}_{3}\right)}
$$




\section{Discussions and Conclusions}

In order to understand the physical situation, we have calculated the numerical values of the velocity distribution (Figure 1 and Figure 2), Angular velocity distribution (Figure 3 and Figure 4), Temperature distribution (Figure 5), Concentration distribution (Figure 6), skin friction ( Figure 7) Nusselt number (Figure 8) for different parameter entered into the problem

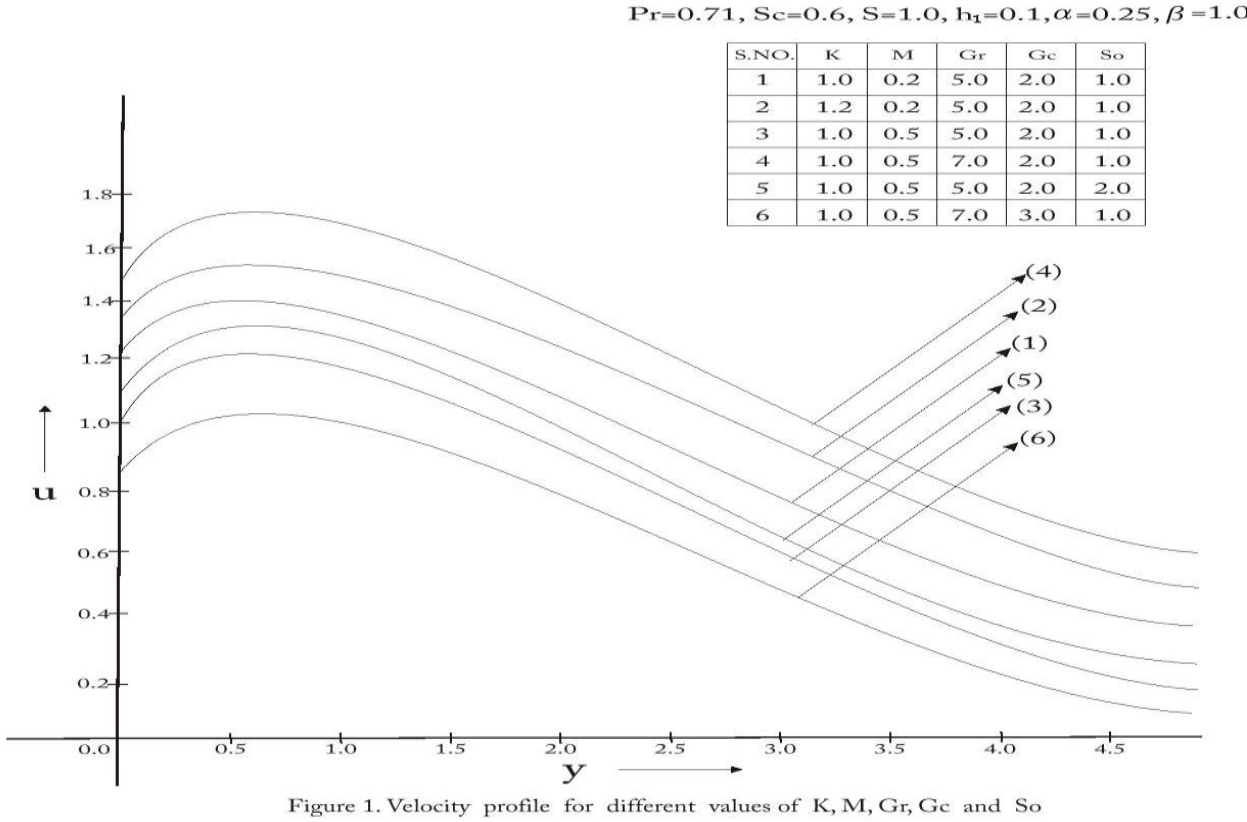

In Figure 1 the velocity distribution is plotted against $\mathrm{y}$ for fixed values of $\operatorname{Pr}=0.71, \mathrm{Sc}=0.6, \mathrm{~S}=1.0, \mathrm{~h}_{1}=0.1$, $\alpha=0.25$ and $\beta=1.0$. It is being observed that when $\mathrm{K}, \mathrm{Gr}$ and $\mathrm{S}_{\mathrm{o}}$ are increased velocity increased but for the case of M and Gc the velocity decreased. Physically, we say that increase in K increased the flow space in the porous medium hence velocity increase.

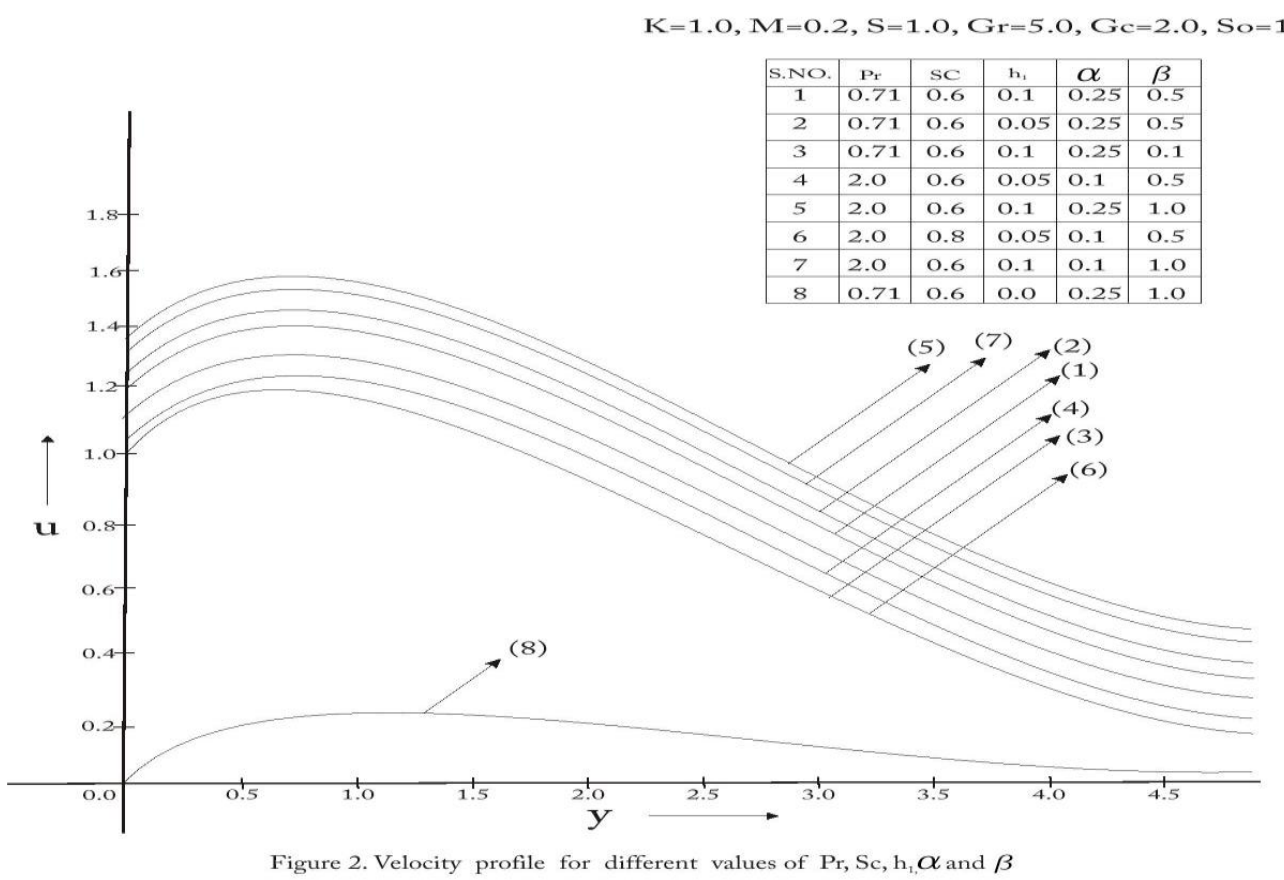

In Figure 2, the velocity distribution is plotted against y for $\mathrm{K}=1.0, \mathrm{M}=0.2, \mathrm{~S}=1.0, \mathrm{Gr}=5.0, \mathrm{Gc}=$ 2.0 and $\mathrm{S}_{\mathrm{o}}=1.0$. It is being observed that when $\operatorname{Pr}, \mathrm{h}_{1}$ and $\alpha$ are increased velocity is increased, but increase in 
Sc and $\beta$ decrease the velocity. It is further observed that when $h_{1}=0$ (No slip condition) velocity is decreased as compared to when $\mathrm{h}_{1} \neq 0$ it means slip velocity increase the velocity of the fluid.
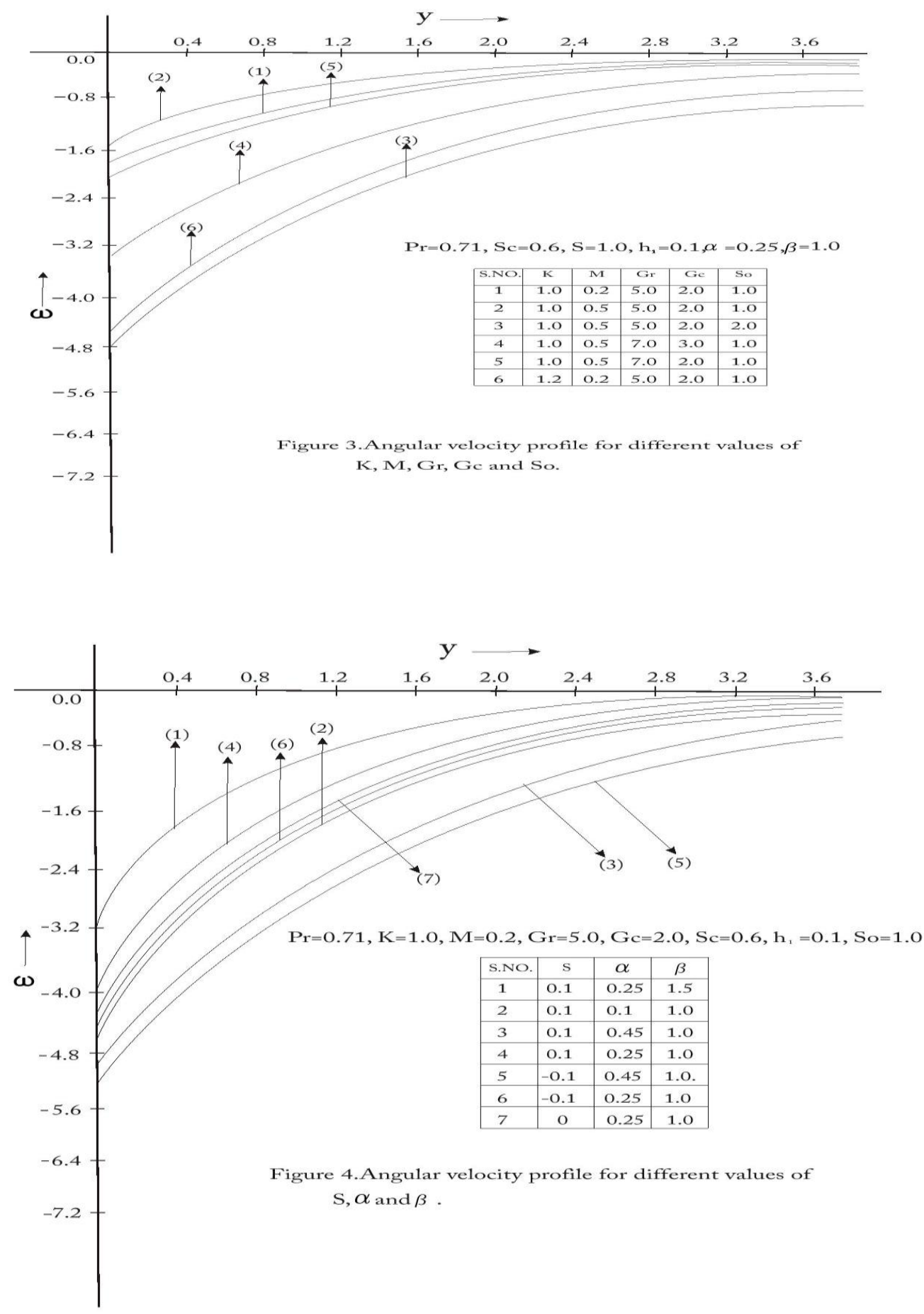

From figures 3 and 4, we observe that angular velocity is less for higher values of $\mathrm{K}, \mathrm{Gr}, \mathrm{Gc}$ and $\mathrm{S}_{0}$ and more with the higher values of $\beta$ and $\mathrm{M}$. As expected, effect of couple stress parameter leads to rise in angular velocity but effect of rotational parameter lead to fall in angular velocity. Moreover, decrease in radiation parameter decreases the angular velocity.

Temperature distribution is plotted against y in Figure 5. It is observed that temperature of the fluid is more in case of air $(\mathrm{Pr}=0.71)$ in Comparison with Water $(\mathrm{Pr}=7.0)$. Moreover, increase in radiation parameter leads to fall in temperature for both the basic fluids. It is further observed that for the case of water negative of radiation parameter increase the temperature of the fluid. 


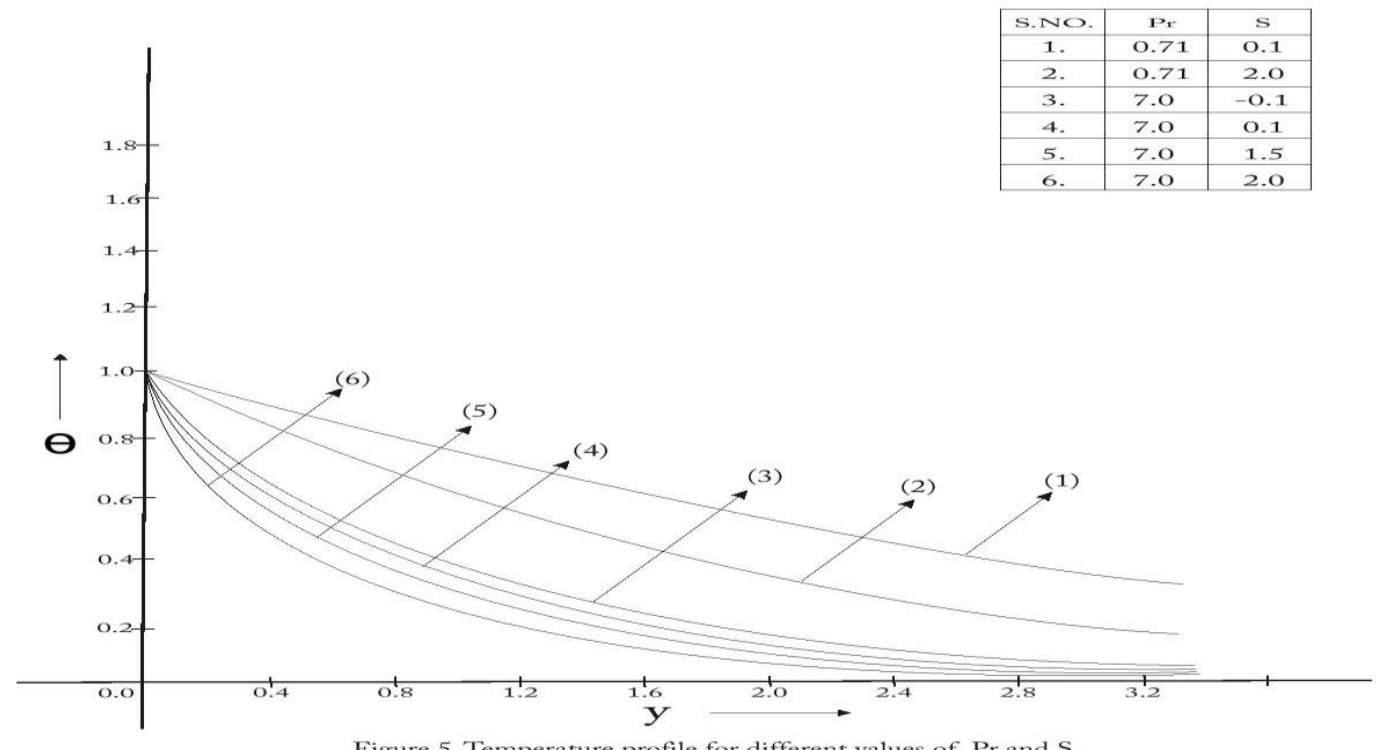

Figure 5. Temperature profile for different values of $\operatorname{Pr}$ and S.

Concentration profile is plotted in figure 6 and it is noticed that concentration is more for hydrogen ( $\mathrm{Sc}$ $=0.22$ ) but less for propyl benzene ( $\mathrm{Sc}=2.62$ ). It is being observed that effect of Sorret number leads to rise in concentration profile.

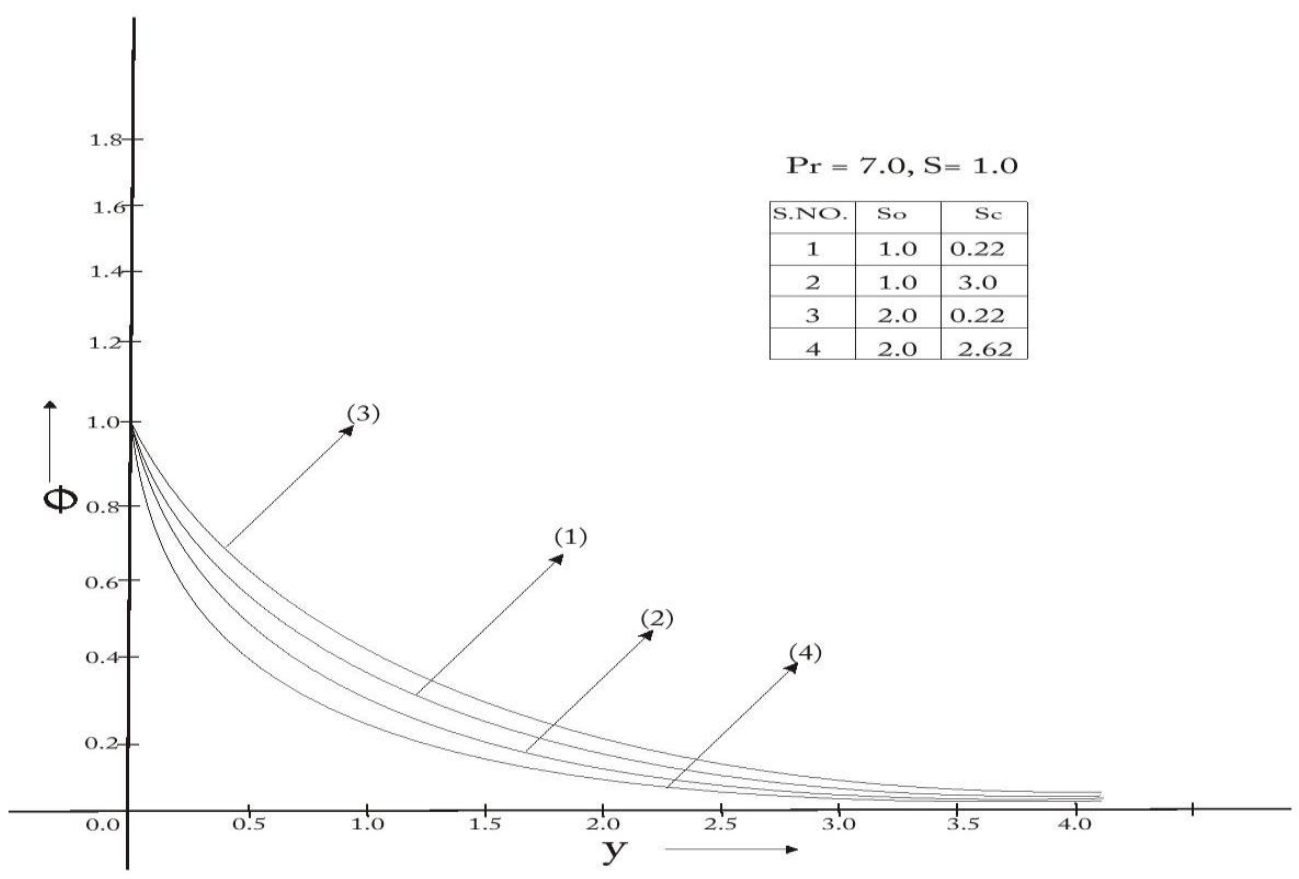

Figure 6. Conentration profile for different values of So and Sc. 


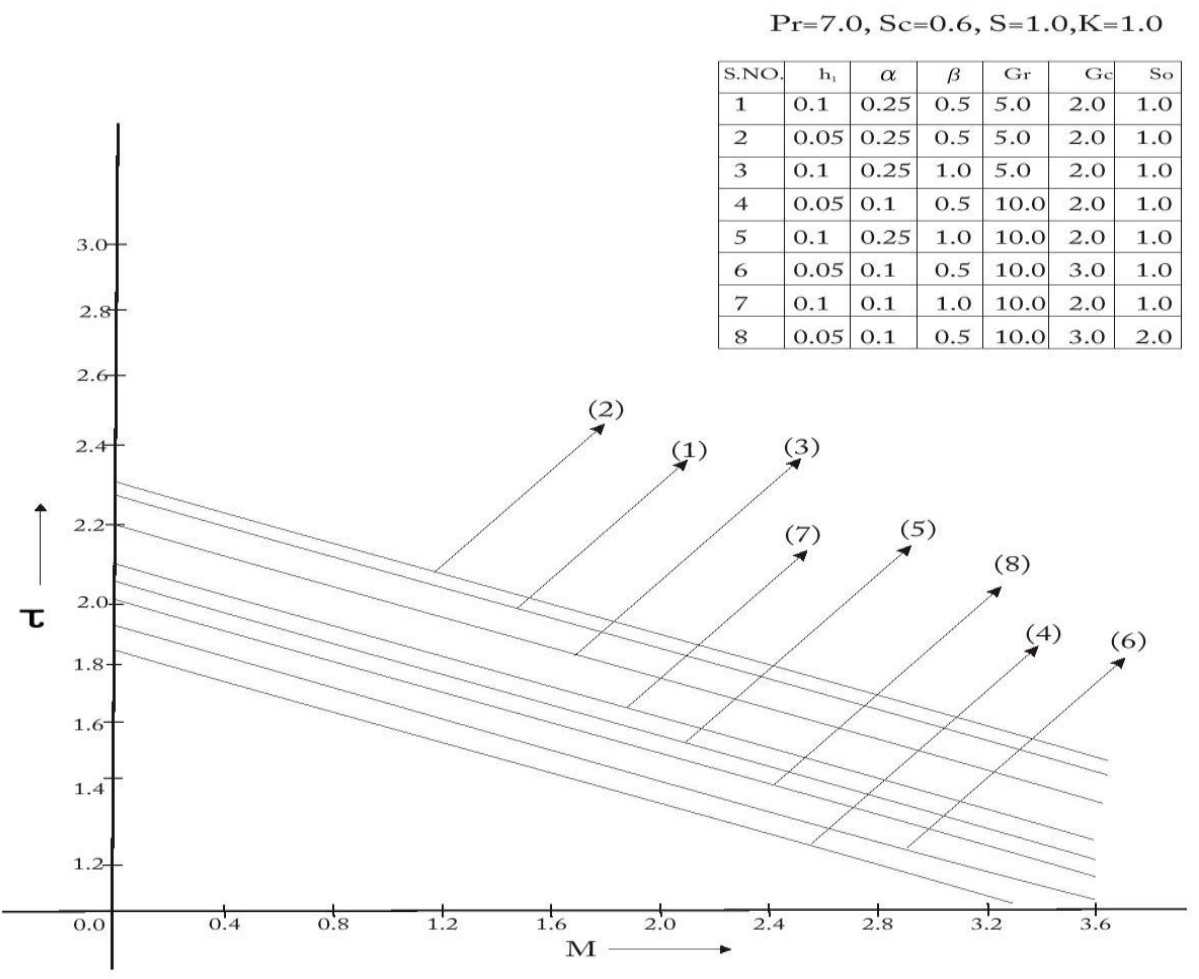

Figure 7. Skin friction for different values of $\mathrm{h}_{1}, \alpha, \beta, \mathrm{Gr}, \mathrm{Gc}$ and So

In figure 7, dimensionless skin friction is plotted against $M$ for different values of $h_{1}, \alpha, \beta, G r, G c$ an $S_{0}$. It is being observed that increase in $h_{1}, G r, \alpha$ and $\beta$ decreases the skin friction but increase in Gc and $S_{o}$ increases the skin friction.

Important parameter namely Nusselt number are plotted in figure 8. it is being concluded that rate of heat transfer is more for Water $(\operatorname{Pr}=7.0)$ in Comparison with air $(\operatorname{Pr}=0.71)$. it is observed that increase in slip parameter increases the Nusselt number for both the basic fluids air and water.

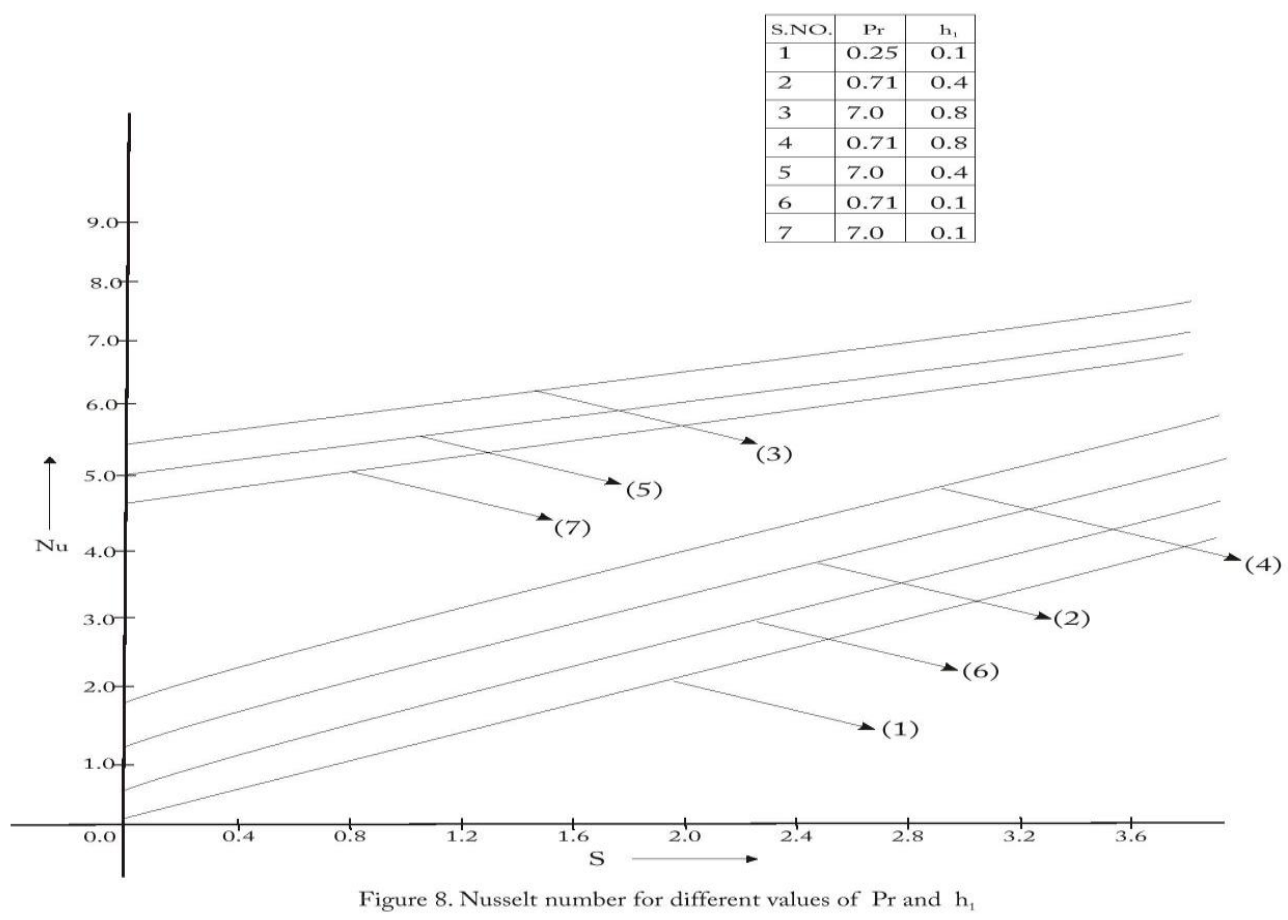




\section{Referensce}

[1]. Brinkman, H.C., 1974. A Calculation of viscous force Extend by a flowing fluid on a Dense Swarm of Particles, Journal of Applied Science, A1, 27-34.

[2]. Chawla, S.S., and Singh, S., 1979.Oscillatory flow past a porous Bed. Acta Mechanica, 34, $205-213$.

[3]. Yamamota, K., and Yoshida, Z., 1974. Flow through a Porous Wall With Convection Acceleration, Journal of Phys Soc. Japan, 37, 774-779.

[4]. Nield, D.A., and Bejan, A., 1998. Convection in Porous Media, $2^{\text {nd }}$ edition, Springer-Verlag, Berlin

[5]. Aero, E.L. Bulganian, A.N., and Kuvshinski, E.N., 1965.Asymmetric Hydrodynamics, Journal of Applied Mathematics and Mechanics, 29, 333-346.

[6]. Lukaszewicz, G., 1999. Micropolar fluids, Theory and Applications, Birkhuaser, Berlin.

[7]. Raptis, A., Peredikis, C., and Tzivanidis, G., 1981. Free convection flow through a Porous Medium Bounded by a Vertical Surface, Journal of Phys. D. Appl. Phys., 14L, 99-102.

[8]. Raptis, A., and Takhar, H.S., 1999. Polar fluid through a Porous Bed, Acta Mechanica, 135, 91-93.

[9]. Saxena, S.S., and Dubey, G.K., 2011. Unsteady MHD Heat and Mass Transfer free Convection flow of Polar fluids Past a Vertical Moving Porous plate in a Porous Medium with Heat Generation and Thermal diffusion, Advances in Applied Science Research, 2(4), 259-278.

[10]. Jain, N.C., Chaudhary, D., and Jat, R.N., 2010. Effects of Radiation and Couple stress parameters on unsteady Mangetopolar free Convection Flow with Mass Transfer and Thermal Radiation in Slip flow regime, Journal of Energy, Heat and Mass Transfer, 32, 333-346.

[11]. Jain, N.C., and Gupta, P., 2007. Unsteady Magnetopolar free Convection flow in Slip flow Regime With Variable Permeability and Constant Heat flux, Journal of Energy, Heat and Mass Transfer, 29, 227-240.

[12]. Jain, N.C., and Gupta, P., 2006. Effects of Rotational Parameter on Unsteady Magnetopolar free Convection flow with Thermal Radiation in Slip flow Regime, Ganita Sandesh, 20, 97-110.

[13]. Ahmadi, G., 1976. Self-similar solution of Incompressible Micropolar Boundary Layer flow over a semi infinite plate, International Journal of Engineering Science, 14, 639-646.

[14]. Kim, Y.J., Unsteady Convection flow of Micropolar fluids Past a Vertical Porous Plate Embedded in a Porous Medium, Acta Mechanics, 148, 105-116.

[15]. Shereliff, J.A., 1965. A text book of Magnetohydrodynamics, Pergamon Press, London.

[16]. Ferraro, V.C.A., and Plumpton, C., 1966. An introduction to magneto fluid mechanics, Claranden Press, Oxford.

[17]. Cramer, K.P., and Pai, S.L., 1973. Magneto fluid dynamics for engineers and applied physics, Mc-Graw Hill Book Company, New York.

[18]. England, W.G., and Emery, A.F., 1969. Thermal Radiation Effects on the Laminar free Convection Boundary layer of an Absorbing Gas, Journal of Heat Transfer, 91, 37-44.

[19]. Chandrakala, P., and Antony Raj, S., 2007. Radiative Heat and Mass Transfer Effects on Moving Isothermal Vertical plate in the presence of Magnetic field, Indian Journal of Mathematics, 49, 289-302.

[20]. Soundalgekar, V.M., and Takhar, H.S., 1993. Radiation Effects on Free Convection Flow Past a Semi-infinite Vertical Plate, Modelling Measurement and Control, B51, 31-40.

[21]. Jothimani, S., and Anjali Devi, S.P., 2001. MHD Couette flow With Heat Transfer and Slip flow Effects in an Inclined channel, Indian Journal of Mathematics, 43, 47-62.

[22]. Khandelwal, A.K., and Jain, N.C., 2006. Effects of Slip Parameter on Unsteady MHD free Convection Mass Transfer flow through Porous Medium of Variable Permeability with Radiation, Ganita Sandesh, 57, 11-20.

[23]. French, A.R., and Norton, W.W., 1971. Newtonian Mechanics, Norton Book Company, New York, 528-529. 